\title{
The role of activity-related groups in assessing workload in the accident and emergency department
}

\author{
P. W. CRONE \& M. R. WHITLOCK \\ Accident \& Emergency Department, Barnet General Hospital, Barnet, Herts
}

\section{SUMMARY}

Workload of the Accident \& Emergency (A\&E) Department at Barnet Generall Hospital was studied over a 1-year period. All new patients were divided into $\vec{\Phi}$ Activity-Related Groups (ARGs). Doctor work hours, for the year, were calculated $\bar{\Xi} \frac{\bar{\sigma}}{\mathrm{O}}$ utilizing the ARGs. This provided an estimate of the minimum required staffing level.

ARGs are a potentially useful tool in auditing workload of individual doctots and the department as a whole.

\section{INTRODUCTION}

The main purpose of medical audit is to identify ways of improving both the quality and the efficiency of clinical care (Royal College of Physicians, 1989). A\&E. work differs from other disciplines in that it administers to a large number of $f_{3}^{\frac{1}{3}}$ patients.

The amount of work undertaken is currently measured by the number of patients 3 . seen. It has been suggested that for every 5000 new patients seen one doctor iso required (Kirby, 1992). This assumes that each patient takes a similar amount of doctor time. Other studies have looked at the time spent on each patient but have concluded that most patients have a trivial problem (NHS, 1983).

Workload in A\&E could be defined more accurately by utilizing ARGs. The concept of ARGs was first described by Miles (1990) who divided patients into. four groups relating both to severity of illness and average time spent. Tachakra 0 et al. (1990) suggested it could be used to assess the workload of a department using a computer.

Correspondence: M. R. Whitlock, Consultant, Accident \& Emergency Department, Barnet General Hospital, Wellhouse Lane, Barnet, Herts EN5 3DJ. 
ARGs were incorporated into the discharge screen on installation of the computer into the A\&E Department at Barnet General Hospital in June 1990. The system uses the Unisys (Burroughs) B25 system installed by Footman Walker (Grout et al., 1989). The number of ARG's was increased to five (Table 1).

\section{METHODS}

A prospective study was performed on all new patients seen in the A\&E Department of Barnet General Hospital over a 1-year period (1 January-31 December 1991). Patients were assigned to one of the five ARGs on discharge. The discharge details were completed by the examining doctor. The definition of each group was by a combination of total time the A\&E doctor was directly involved with the patient, and severity of illness (Table 1). Nursing time was not accounted for.

Workload was divided into three time periods over $24 \mathrm{~h}$, relating to the Department's current staffing levels. Doctor hours were calculated from the time allocated to each ARG. Group V (DOA) was excluded from this analysis because nurse time exceeds doctor involvement.

\section{RESULTS}

During the year studied, 35708 new patients were registered. Discharge details were complete in $34471(96 \%)$ of these.

Analysis of the 34471 patients revealed that those falling into ARG 1 constituted 46\%; whilst ARG II and ARG III each constituted 27\%. Patients requiring resuscitation (ARG IV) were a minority at $0.5 \%$ (Table 2 ).

There was no significant difference between the proportion of patients in Groups I, II and III presenting within the three time periods. (Table 3) The proportion of

Table 1. Activity-related groups (ARGs)

\begin{tabular}{|c|c|c|}
\hline & & Time spent \\
\hline \multicolumn{3}{|c|}{ Minor } \\
\hline I & $\begin{array}{l}\text { Patient seen and treated in one } \\
\text { consultation }\end{array}$ & $\leq 15 \min$ \\
\hline II & $\begin{array}{l}\text { Patient requires investigation, } \\
2 \text { consultation, referral, etc. }\end{array}$ & $15-30 \mathrm{~min}$ \\
\hline \multicolumn{3}{|c|}{ 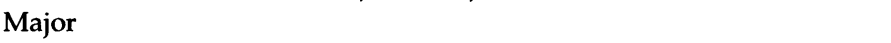 } \\
\hline III & $\begin{array}{l}\text { Patient requires more detailed } \\
\text { history, examination, treatment, } \\
\text { referral, etc. }\end{array}$ & $30-45 \mathrm{~min}$ \\
\hline IV & Patient requires resuscitation & $30-90 \mathrm{~min}$ \\
\hline V & Patient pronounced dead on arrival & \\
\hline
\end{tabular}


Table 2. Patients divided into ARGs

\begin{tabular}{lcc}
\hline ARG & Number & Percentage \\
\hline I & 15715 & 45.6 \\
II & 9109 & 26.4 \\
III & 9401 & 27.3 \\
IV & 160 & 0.5 \\
V & 85 & 0.2 \\
Total & 34471 & \\
\hline
\end{tabular}

Table 3. Time of presentation

\begin{tabular}{lrrr}
\hline ARG & $0800-1659$ & $1700-2359$ & $0000-0759$ \\
\hline I & $8600-55 \%$ & $5728-36 \%$ & $1387-9 \%$ \\
II & $5044-56 \%$ & $3133-34 \%$ & $932-10 \%$ \\
III & $5058-54 \%$ & $3180-34 \%$ & $1163-12 \%$ \\
IV & $66-41 \%$ & $56-35 \%$ & $38-24 \%$ \\
Total & $18768-55 \%$ & $12097-35 \%$ & $3520-10 \%$ \\
\hline
\end{tabular}

Table 4. Workload measured in doctor hours for 12 months

\begin{tabular}{lcccr}
\hline ARG & $0800-1659$ & $1700-2359$ & $0000-0759$ & TOTAL \\
\hline I (15 min) & 2150 & 1432 & 347 & 3929 \\
II (30 min) & 2522 & 1567 & 466 & 4555 \\
III (45 min) & 3794 & 2385 & 872 & 7051 \\
IV (60 min) & 66 & 56 & 38 & 160 \\
$\begin{array}{l}\text { Total } \\
\quad \text { Doctor hours } \\
\text { divided by hours }\end{array}$ & 8532 & 5440 & 1723 & 15695 \\
$\begin{array}{l}\text { per year } \\
\text { Equals }\end{array}$ & 3285 & 2555 & 2920 & \\
$\quad \begin{array}{l}\text { Number of } \\
\text { doctors needed }\end{array}$ & 2.6 & 2.1 & & \\
\hline
\end{tabular}

patients requiring resuscitation (ARG IV) between midnight and 8 a.m. (24\%) waš higher than that of other patient groups presenting in the same period.

The workload of the Department, expressed in doctor hours, for the three time periods over $24 \mathrm{~h}$ is shown in Table 4 . Estimation of the number of doctors required per time period revealed a minimum of three between 8 a.m. and 5 p.m.; two? between 5 p.m. and midnight; and one from midnight to 8 a.m. (Table 4). 


\section{DISCUSSION}

The first step in clinical audit is to 'observe practice - find out what is actually happening' (Royal College of Physicians, 1989). The workload of the A\&E Department has been observed in terms of doctor work hours. The calculated minimum number of doctors required per time period in Barnet's A\&E Department is currently met from Monday to Friday. The weekends are probably staffed inadequately with a maximum of two doctors at any one time. It is proposed to further compare the workload between days of the week and implement appropriate staffing levels.

This is the first reported series of ARGs in A\&E. It is interesting that ARG II and III each represented $27 \%$ of patients. Perhaps ARG III needs further subdivision between patients requiring acute management and re-assessment by the A\&E doctor (time $45-60 \mathrm{~min}$ ), and those who do not (time $30-45 \mathrm{~min}$ ). It is planned to update the discharge screen at Barnet incorporating six ARGs, and study this further.

The time assigned to a group needs further validation. It is difficult to measure this accurately. The time alloted to each group in this study (Table 1) - a building block of $15 \mathrm{~min}$ - suggested the department was staffed adequately, except for the weekends.

Patients, excluding resuscitation cases, requiring more than $60 \mathrm{~min}$ of an $\mathrm{A} \& \mathrm{E}$ doctor's time, should be noted as special cases in discharge details. Close review of these cases could identify ways of improving the efficiency of care.

Other A\&E departments have incorporated ARGs into their discharge details. It would be valuable to compare patient ARGs and workload between hospitals.

ARGs can be used as a Performance Indicator to provide adequate staffing levels of doctors and nurses. Whether appropriate staffing levels improve the quality of patient care requires further study.

Hospital management should use workload rather than the number of patients seen when ascertaining true costs for a department.

\section{REFERENCES}

Grout P., Hunt M. T. \& Touquet R. (1989) The benefits of an accident and emergency computer system. Theoretical Surgery 4, 1-9.

Kirby N. G. (1992) The Way Ahead. Accident and Emergency Services 2001, 5, 1. British Association for Accident and Emergency Medicine, London.

Miles S. (1990) A Consultation Document for the Casualty Surgeons Association, Vol. 1, pp. 3.

National Health Service (1983) Compendium of Efficiency Studies 2, 15.

Royal College of Physicians (1989) Medical Audit: A First Report - What, Why and How, pp. 1-11. Report of the Royal College of Physicians.

Tachakra S. S., Potts D. \& Idowu A. (1990) Evaluation of a computerised system for medical records in an accident and emergency department. International Journal of Clinical Monitoring and Computation 7, 187-191. 